\title{
Screening for potential familial hypercholesterolaemia in general practice: an observational study on prevalence and management
}

\section{Stefan Mülverstedt, MD*, Per Rossen Hildebrandt, MD, DMSc ${ }^{2}$, Eva Prescott, MD, DMSc ${ }^{1}$, Merete Heitmann, MD, PhD ${ }^{1}$}

${ }^{1}$ Department of Cardiology, Copenhagen University Hospital, Bispebjerg, Copenhagen, Denmark; ${ }^{2}$ Heart Clinic Frederiksberg, Frederiksberg, Denmark

\begin{abstract}
Background: Familial hypercholesterolaemia $(\mathrm{FH})$ is a common genetic disorder causing premature cardiovascular disease (CVD). The estimated prevalence of probable or definite FH is 1:200-250 individuals, according to the Dutch Lipid Clinic Network (DLCN) criteria for FH. In Denmark approximately $12 \%$ of cases are identified.
\end{abstract}

Aim: To provide knowledge of the prevalence and management of $\mathrm{FH}$ in general practice.

Design \& setting: A collaboration between six general practice clinics and the department of cardiology at Bispebjerg hospital in Denmark.

Method: A total of 9652 patient records were screened for hypercholesterolaemia. All patients with a low-density lipoprotein cholesterol (LDL-C) $\geq 5.0 \mathrm{mmol} / \mathrm{l}$ were included in the study population and their records were investigated in order to perform a diagnostic score according to the DLCN criteria.

Results: It was found that 2382 individuals had a lipid measurement available, and 236 of those had

*For correspondence: science. mulver@gmail.com

Competing interest: The authors declare that no competing interests exist.

Received: 04 June 2020 Accepted: 01 July 2020 Published: 03 February 2021

(C)This article is Open Access: CC BY license (https://creativecommons.org/licenses/by/4.0/)

Author Keywords: familial hypercholesterolaemia, mass screening, general practice, lipid lowering therapy, cardiovascular diseases

Copyright (C) 2020, The Authors; DOI:10.3399/

bjgpopen20X101142 an LDL-C $\geq 5.0 \mathrm{mmol} / \mathrm{l}$. In total, 34 individuals were found to have probable or definite FH (DLCN score $\geq 5$ ). Only three individuals had been diagnosed and treated with lipid-lowering therapy. Of 236 individuals with high LDL-C, only 25 individuals met their treatment target. By excluding patients with signs of secondary hypercholesterolaemia, a subgroup of 115 individuals with potential primary hypercholesterolaemia was established. Among those, 21 individuals were found to have probable or definite $\mathrm{FH}$ (1:114 individuals).

Conclusion: The study shows that there is a massive lack of recognition of $\mathrm{FH}$ in general practice. Despite a measured high LDL-C, the diagnosis is rarely made and only a few patients are treated accordingly. Of the patients undergoing treatment, only a few reached their treatment target.

\section{How this fits in}

$\mathrm{FH}$ is significantly underdiagnosed in general practice. This study therefore aimed to establish the extent of FH diagnosis in general practice in Denmark. Referral of potential patients with FH was not sufficient, even when FH was suspected by the GP. Individuals suspected of FH did not meet their LDL-C treatment target. Only half of the population with LDL-C $\geq 5 \mathrm{mmol} / \mathrm{l}$ underwent lipid-lowering therapy. 


\section{Introduction}

$\mathrm{FH}$ is a common genetic disorder that causes premature coronary heart disease and myocardial infarction (MI), which is because of a lifelong elevated level of LDL-C. If left untreated, individuals with heterozygous $\mathrm{FH}$ often develop coronary artery disease at an early age. ${ }^{1,2}$

The lack of recognition and undertreatment of individuals with $\mathrm{FH}$ in the general population is largely unknown worldwide, but based on assessment of 98098 individuals in the Copenhagen General Population Study, FH-causing mutations were estimated to occur in 1:217 individuals in the general Danish population. ${ }^{3}$

Other population studies have made similar estimates and it is generally accepted that the prevalence of $\mathrm{FH}$ in the general population is 1:200-250 individuals. ${ }^{4-6}$ In Denmark only about $12 \%$ of the individuals with $\mathrm{FH}$ have been identified. ${ }^{4}$ In other countries elaborate screening interventions have raised the rate of identified patients with $\mathrm{FH}$ considerably. $4,7,8$

The prevalence of $\mathrm{FH}$ has not been directly assessed in an unselected sample of the general population in general practice clinics in Denmark. It has been shown that GPs generally have a good awareness of hyperlipidaemia and lipid-lowering therapy; however, their knowledge and awareness of national guidelines, prevalence, and diagnostic features of $\mathrm{FH}$ is suboptimal. ${ }^{7,9}$ Previous studies have shown that the prevalence of $\mathrm{FH}$ in general practice is underestimated. ${ }^{710}$ In addition, it is unknown whether patients with $\mathrm{FH}$ and hyperlipidaemia reach their treatment target when managed by GPs. From large population studies it is known that patients with $\mathrm{FH}$ in general are undertreated., 10-12

This study aimed to provide knowledge of the prevalence and management of $\mathrm{FH}$ in general practice. In addition, the authors wanted to evaluate the perspective for applying an algorithm as a screening tool for FH. Furthermore, they wanted to evaluate the extent and efficacy of lipid-lowering therapy among individuals with high LDL-C levels.

\section{Method}

This is a retrospective observational register-based study performed in collaboration with six GP clinics in the municipality of Copenhagen. The only condition for participation was use of the WinPLC system for handling electronic patient records in the clinic. This system is widely used by GPs in all of Denmark.

The study population consisted of all individuals aged 18-100 years with at least one measurement of LDL-C. These were identified through the search function incorporated in the electronic patient record system (Figure 1).

Information about pre-existing CVD, diabetes mellitus (DM), hypertension, liver disease, and thyroid disease, as well as obesity and high alcohol consumption, was registered from the International Classification of Primary Care (ICPC) codes for classification of diagnoses in primary care. ${ }^{13}$ Information regarding lipid-lowering therapy in the study population was registered from active prescriptions in the Danish medications system.

All individuals with at least one measurement of LDL-C $\geq 5.0 \mathrm{mmol} / \mathrm{l}$ were then identified and included in the high LDL-C population. Individuals on lipid-lowering therapy had their latest recorded LDL-C value, regardless of level, adjusted by multiplying a correction factor according to their active treatment. ${ }^{14,15}$ If this pre-treatment LDL-C was $\geq 5.0 \mathrm{mmol} / \mathrm{l}$ the individual was included in the high LDL-C population (Figure 1). All individuals in the high LDL-C population had their patient records investigated for further information on clinical features, cardiovascular morbidity, and family medical history.

The high LDL-C population was assessed for potential causes of secondary hyperlipidaemia, including a diagnosis of either DM, thyroid disease, liver disease, or alcohol abuse. In addition, blood tests for glycaemic levels (HbA1c), thyroid function (thyroid stimulating hormone [TSH]), kidney function (creatinine), and liver function (alanine aminotransferase [ALT]) were evaluated. Individuals with normal values on these parameters were deemed to have potential primary hyperlipidaemia (Figure 2).

The DLCN criteria for clinical FH of dyslipidaemia for screening was used (Figure 3). ${ }^{16}$

Information concerning clinical findings according to the DLCN criteria were registered as 'met' or 'not met'. The highest measured value of LDL-C was used with adjustment for lipid-lowering therapy. In terms of relatives' cholesterol levels, only first-degree relatives with an estimated LDL-C above 95th 
9652 individuals - GP population

All individuals aged $18-100$ years affiliated to six GP clinics in Copenhagen

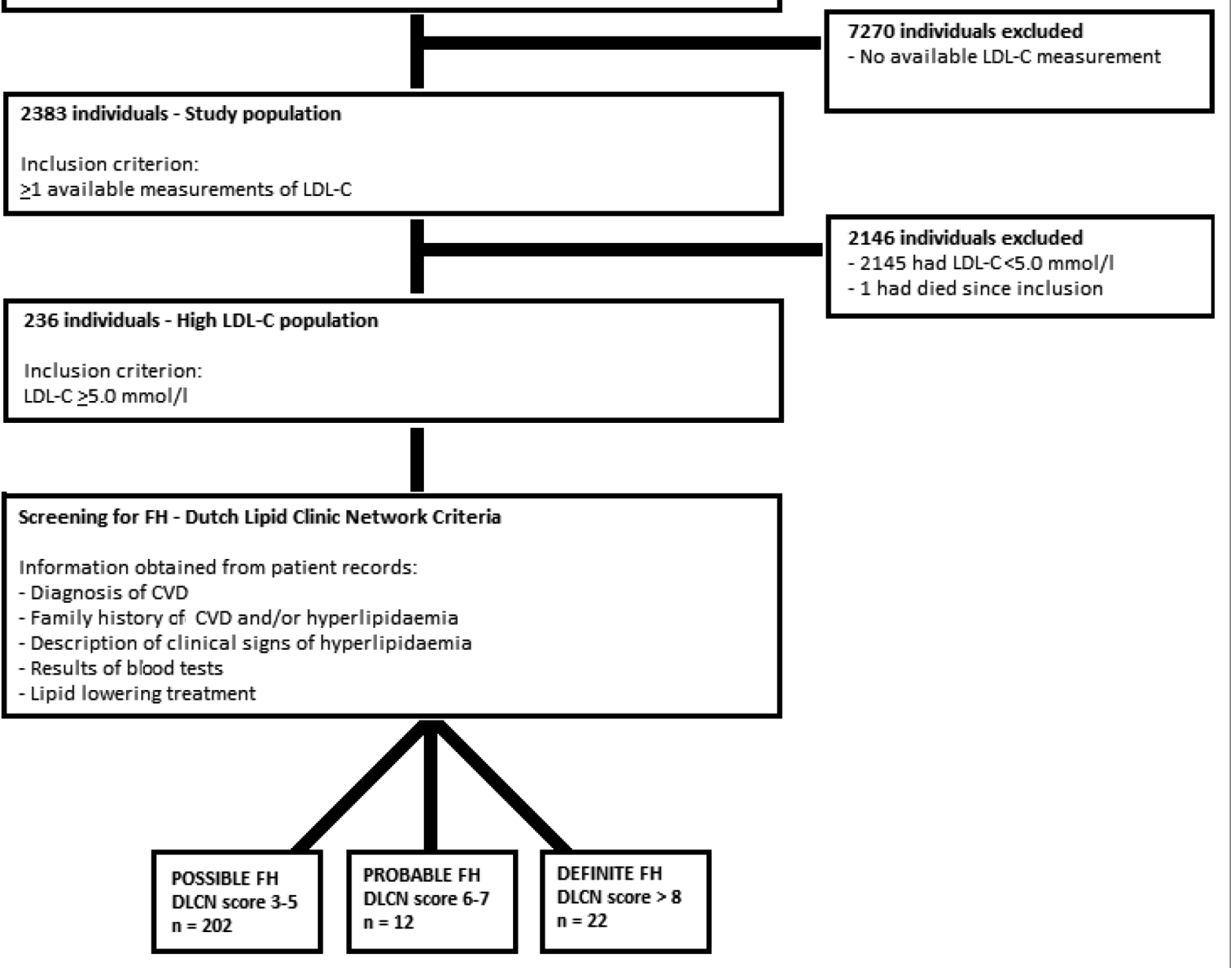

Figure 1 Flowchart of inclusion and exclusion throughout the study. The study population consisted of all patients with $\geq 1$ available LDL-C measurements. The high LDL-C population ( $n=236$ individuals) consisted of patients with $\geq 1 \mathrm{LDL}-\mathrm{C}$ reported $\geq 5.0 \mathrm{mmol} / \mathrm{l}$. CVD $=$ cardiovascular disease. DLCN = Dutch Lipid Clinic Network. FH = familial hypercholesterolaemia. LDL-C = low-density lipoprotein cholesterol

percentile contributes to the patient's DLCN score, but information regarding family medical history in the patient records has been interpreted in the broadest possible way.

Tendinous xanthomata and arcus cornealis were included in the DLCN score if it was described in the medical record. Follow-up clinical confirmation was not performed as this is not allowed according to Danish legislation.

For identification of individuals with probable or definite $\mathrm{FH}$, the DLCN criteria (Figure 3) was then applied to the individuals in the high LDL-C population and to the subgroup of individuals without secondary hypercholesterolaemia (Figure 2).

Furthermore, the extent and efficacy of lipid-lowering therapy were evaluated. The treatment targets were used from the 2016 European Society of Cardiology (ESC) and European Atherosclerosis Society (EAS) guidelines for management of dyslipidaemia. ${ }^{16}$ The number of patients reaching the actual target values were evaluated (LDL-C $<1.8 \mathrm{mmol} / \mathrm{l}$ for very high risk and LDL-C $<2.6 \mathrm{mmol} / \mathrm{l}$ for high risk) and the number of patients reaching a reduction of LDL-C of $>50 \%$ from baseline was estimated. 


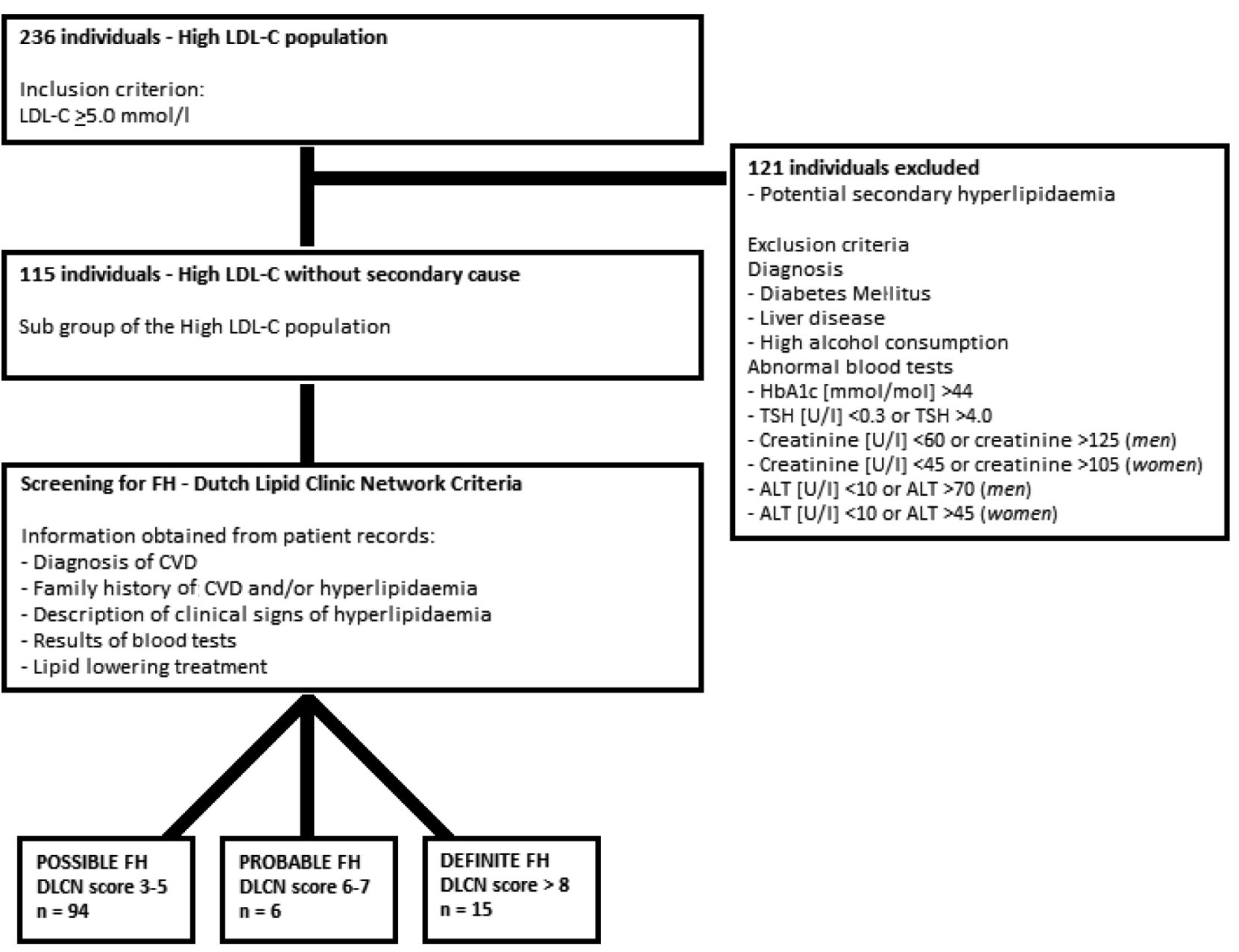

Figure 2 Flowchart of the analysis of the subgroup of individuals deemed to have primary hypercholesterolaemia. The high LDL-C population is defined as individuals with a reported LDL-C $\geq 5.0 \mathrm{mmol} / \mathrm{I}$ (Figure 1). ALT = alanine aminotransferase. CVD = cardiovascular disease. DLCN = Dutch Lipid Clinic Network. FH = familial hypercholesterolaemia. $\mathrm{LDL}-\mathrm{C}=\mathrm{Low}$-density lipoprotein cholesterol. TSH = thyroid stimulating hormone

\section{Statistical analyses}

Descriptive data are presented as means with standard deviation (SD) or interquartile range (IQR). Comparison of means are calculated using $t$-tests. A $P$-value $<0.05$ is considered significant. All statistical analyses were performed using Stata (version 13) software.

\section{Results}

The six GP clinics saw a total 9652 individuals between 18 years and 100 years of age (Figure 1). Of those, 2382 individuals had $\geq 1$ measurements of LDL-C and were included in the study population. In total, 237 (9.9\%) individuals had at least one measure of LDL-C $\geq 5.0 \mathrm{mmol} / \mathrm{l}$. Baseline characteristics for both groups are presented in Table 1. One individual with LDL-C $\geq 5.0 \mathrm{mmol} / \mathrm{l}$ was deceased leaving 236 to be included in the high LDL-C population.

\section{FH diagnostic}

The DLCN criteria were applied to the 236 individuals in the high LDL-C population. Of this subgroup, $34(14.4 \%)$ individuals were identified with probable or definite $\mathrm{FH}$ corresponding to $1.4 \%$ or approximately 1:70 individuals of the study population of 2382 individuals (Table 2).

After excluding all individuals with possible secondary dyslipidaemia from the high LDL-C population, a subgroup of 115 individuals were deemed to have primary hypercholesterolaemia. By applying these criteria 13 individuals with probable or definite $\mathrm{FH}$ were also excluded. Of the 


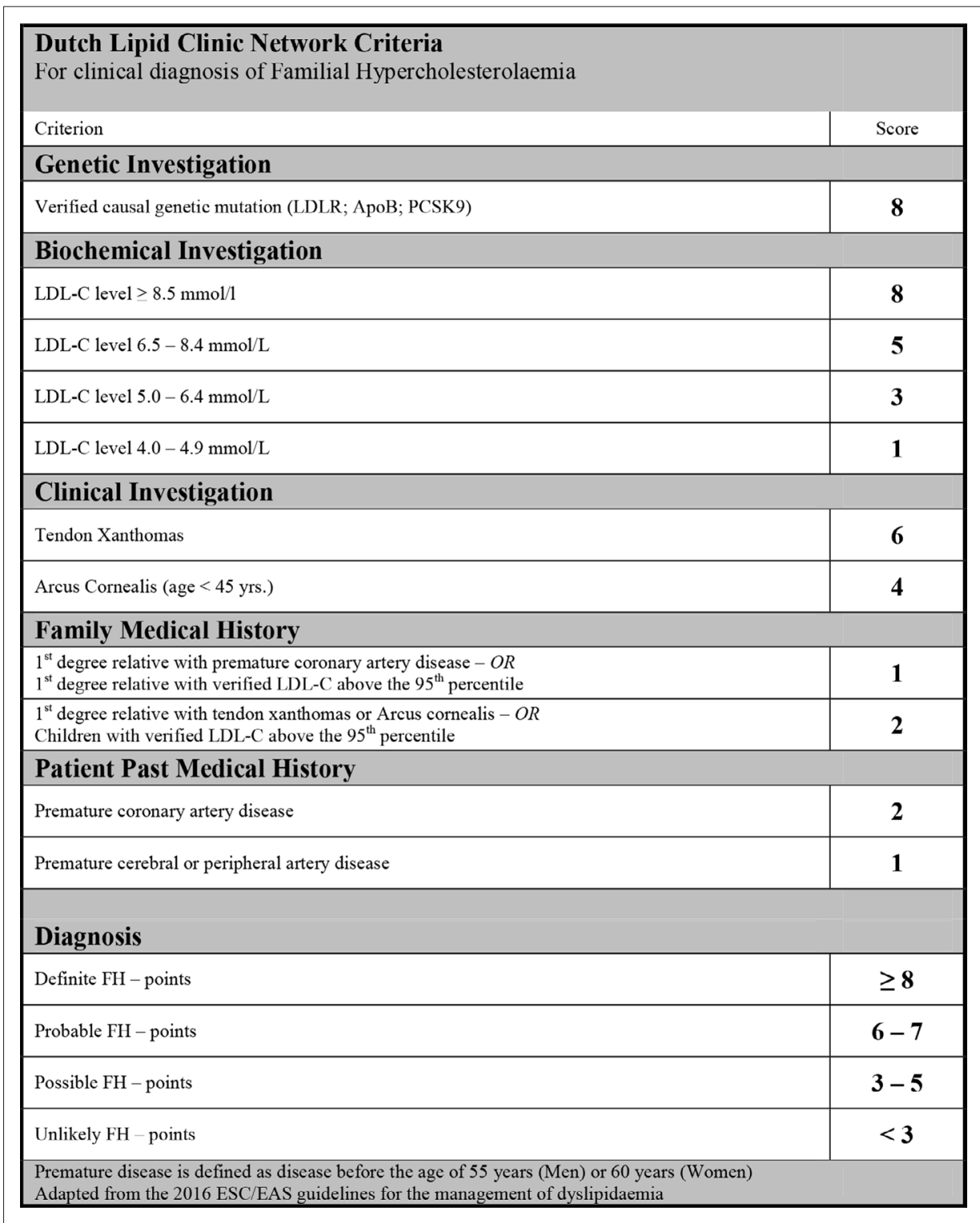

Figure 3 Diagnostic criteria. ApoB = apolipoprotein B. FH = familial hypercholesterolaemia. LDLR = low-density lipoprotein receptor. PCSK9 = proprotein convertase subtilisin/kexin type 9

subgroup, 21 individuals ( $0.9 \%$ of the study population) had probable or definite $\mathrm{FH}$, corresponding to $1: 114$ individuals.

Only 152 individuals (64.4\%) in the high LDL-C population had records of a family history. Clinical signs of dyslipidaemia were described in one individual.

A total of 82 individuals (34.7\%) of the high LDL-C population had been referred to treatment by a cardiologist and four of these individuals were referred to a lipid clinic. Sixty-two (26.3\%) had been referred to another internal medicine outpatient clinic. The remaining 92 individuals (39.0\%) had not been referred to any specialist (Table 3 ).

\section{Medical treatment}

Lipid-lowering therapy, predominantly statins, were prescribed to 122 individuals $(51.7 \%)$ in the high LDL-C population. The proportion of prescribed lipid-lowering therapy tended to be higher in the groups with probable and definite FH compared with the entire high LDL-C population. Furthermore, 33 individuals had previously been on lipid-lowering therapy, but for some reason they had come off their treatment (data not shown). Ezetimibe was prescribed to four individuals and only one individual 
Table 1 Baseline characteristics

\begin{tabular}{|c|c|c|}
\hline & Study population, $n$ (\%) & Hypercholesterolaemia (LDL-C $\geq 5.0 \mathrm{mmol} / \mathrm{l}$ ), $n$ \% \\
\hline Total & $2382(100.0)$ & 237 (9.9) \\
\hline Age, years, mean (IQR) & $52.6(19.1-98.9)$ & $63.9(26.9-93.4)$ \\
\hline Sex, Male & $1047(44.0)$ & $111(46.8)$ \\
\hline \multicolumn{3}{|l|}{ Cardiovascular disease } \\
\hline Ischaemic heart disease & $116(4.9)$ & $31(13.1)$ \\
\hline $\mathrm{Ml}$ & $41(35.3)$ & $9(29.0)$ \\
\hline AP & $56(48.3)$ & $18(58.1)$ \\
\hline $\mathrm{CHF}$ & $30(25.9)$ & $5(16.1)$ \\
\hline $\mathrm{PCl}$ & $11(9.5)$ & $2(6.5)$ \\
\hline CABG & $9(7.8)$ & $1(3.2)$ \\
\hline$A P(n \circ \mid H D)$ & $49(2.1)$ & $8(3.4)$ \\
\hline Cerebrovascular disease & $103(4.3)$ & $26(11.0)$ \\
\hline Stroke & $70(68.0)$ & $19(73.1)$ \\
\hline $\mathrm{TCl}$ & $47(45.6)$ & $10(38.5)$ \\
\hline Peripheral artery disease & $49(2.1)$ & $10(4.2)$ \\
\hline \multicolumn{3}{|l|}{ Comorbidity } \\
\hline Hypertension & $454(19.1)$ & $115(48.5)$ \\
\hline Diabetes & $146(6.1)$ & $30(12.7)$ \\
\hline Type 1 & $11(7.5)$ & $2(6.7)$ \\
\hline Type 2 & $135(92.5)$ & $28(93.3)$ \\
\hline Hyperthyroid disease & $60(2.5)$ & $9(3.8)$ \\
\hline Hypothyroid disease & $116(4.9)$ & $22(9.3)$ \\
\hline Liver disease & $60(2.5)$ & $20(8.4)$ \\
\hline Viral hepatitis & $18(0.8)$ & $2(0.8)$ \\
\hline Alcohol abuse & $100(4.2)$ & $18(7.6)$ \\
\hline Obesity & $129(5.4)$ & $14(5.9)$ \\
\hline \multicolumn{3}{|l|}{ Medications } \\
\hline Statin & $293(12.3)$ & $119(50.2)$ \\
\hline Ezetimibe & $8(0.3)$ & $4(1.7)$ \\
\hline PCSK9 inhibitor & $1(0.04)$ & $1(0.4)$ \\
\hline ACE inhibitor & $205(8.6)$ & $33(13.9)$ \\
\hline ATIl antagonist & $125(5.2)$ & $21(8.9)$ \\
\hline Beta blockers & $217(9.1)$ & $37(15.6)$ \\
\hline Calcium channel blockers & $270(11.3)$ & $49(20.7)$ \\
\hline Diuretics & $244(10.2)$ & $54(22.8)$ \\
\hline
\end{tabular}

Baseline characteristics of the study population and those individuals with LDL-C $\geq 5.0 \mathrm{mmol} / \mathrm{I}$. All data obtained exclusively through electronic screening of the patient records. $\mathrm{ACE}=$ angiotensin converting enzyme. $\mathrm{AP}=$ angina pectoris. $\mathrm{ATI}=$ angiotensin $\|$ receptor. $\mathrm{CABG}=$ coronary artery by-pass grafting. $\mathrm{CHF}=$ congestive heart failure. IHD = ischaemic heart disease. $\mathrm{MI}=$ myocardial infarction. $\mathrm{PCl}=$ percutaneous intervention. $\mathrm{PCSK9}=$ proprotein convertase subtilisin/kexin type $9 . \mathrm{TCl}=$ transitory cerebral ischaemia. 
Table 2 Identification of potential FH

High LDL-C population (LDL-C $\geq 5.0 \mathrm{mmol} / \mathrm{I}), n \%$

High LDL-C without potential secondary cause (subgroup), $n \%$

\section{Cardiovascular profile}

Total

Ischaemic heart disease

$\mathrm{MI}$

AP

$\mathrm{CHF}$

$\mathrm{PCl}$

CABG

Cerebral vascular disease

Peripheral artery disease

\section{Criteria for clinical FH (DLCN)}

Past medical history

Premature ischaemic heart disease

Premature cerebrovascular disease

Premature peripheral artery disease

\section{Clinical features}

Tendon xanthomas

Arcus cornealis

$0(0.0)$

$1(0.4)$

0

$1(0.9)$

\section{Family medical history}

Family history of ischaemic heart disease

Family history of cerebral vascular disease

Family history of peripheral artery disease

Family history of hyperlipidaemia

No family history available

\section{Result of screening}

Definite FH - DLCN score $>8$

$22(9.3)$

$51(21.6)$

$36(31.3)$

$13(5.5)$

9 (7.8)

4 (1.7)

2 (1.7)

$27(11.4)$

17 (14.8)

$84(35.6)$

$48(41.7)$

$15(13.0)$

Probable FH - DLCN score 6-7

Possible FH - DLCN score 3-5

$202(85.6)$

$6(5.2)$

94 (81.7)

\section{Actual diagnostic yield}

Confirmed diagnosis of $\mathrm{FH}$

FH suspected by GP

$3(1.3)$

1 (0.9)

$26(11.0)$

$22(19.1)$

Subgroup has been derived from the high LDL-C population. Information has been obtained by reading the patient records for all the patients. $\mathrm{AP}=$ angina pectoris. $\mathrm{CABG}=$ coronary artery by-pass grafting. $\mathrm{CHF}=$ congestive heart failure. $\mathrm{DLCN}=$ Dutch Lipid Clinic Network. FH = familial hypercholesterolaemia. $\mathrm{MI}=$ myocardial infarction. $\mathrm{PCl}=$ percutaneous intervention.

was prescribed PCSK9 inhibitors (Table 3). Of 118 individuals in the high LDL-C population receiving statins, 64 (54.4\%) individuals were receiving maximum dosage of statins.

Among patients with CVD $(n=68)$ in the high LDL-C population, $53(77.9 \%)$ received lipid-lowering therapy but only three (4.4\%) reached the treatment target of LDL-C $<1.8 \mathrm{mmol} / \mathrm{l}$, according to the 2016 ESC and EAS guidelines for the management of dyslipidaemia. ${ }^{16}$ It was found that $54.9 \%$ of 
Table 3 Management of patients with potential $\mathrm{FH}, \mathrm{N}=236$

\begin{tabular}{|c|c|c|c|}
\hline & \multicolumn{3}{|c|}{ Result of screening, $n \%$} \\
\hline & $\begin{array}{c}\text { Possible } \\
\text { DLCN score: 3-5 }\end{array}$ & $\begin{array}{c}\text { Probable } \\
\text { DLCN score: 6-7 }\end{array}$ & $\begin{array}{c}\text { Definite } \\
\text { DLCN score: } \geq 8\end{array}$ \\
\hline Total & $202(85.6)$ & $12(5.1)$ & $22(9.3)$ \\
\hline \multicolumn{4}{|l|}{ Outpatient referrals } \\
\hline Lipid clinic & $0(0.0)$ & $0(0.0)$ & $4(18.2)$ \\
\hline Cardiologic outpatient clinic & $49(24.3)$ & $6(50.0)$ & $4(18.2)$ \\
\hline Internal medicine outpatient clinic & $57(28.2)$ & $1(8.3)$ & $4(18.2)$ \\
\hline Private practice cardiologist & $16(7.9)$ & $1(8.3)$ & $2(9.1)$ \\
\hline No referral & $80(39.6)$ & $4(33.3)$ & $8(36.4)$ \\
\hline \multicolumn{4}{|l|}{ Lipid-lowering therapy } \\
\hline Ongoing lipid-lowering therapy & $91(45.0)$ & $11(91.7)$ & $20(90.9)$ \\
\hline Statin therapy & $88(96.7)$ & $11(100)$ & $19(95.0)$ \\
\hline Maximum statin dosage & $49(55.7)$ & $5(45.5)$ & $10(52.6)$ \\
\hline Ezetimibe therapy & $3(3.4)$ & $0(0.0)$ & $1(5.3)$ \\
\hline PCSK9 inhibitor therapy & $0(0.0)$ & $0(0.0)$ & $1(5.3)$ \\
\hline No lipid-lowering therapy & $111(55.0)$ & $1(8.3)$ & $2(9.1)$ \\
\hline \multicolumn{4}{|l|}{ Diagnostic status of FH } \\
\hline FH diagnosis is made & $2(1.0)$ & $1(8.3)$ & $0(0.0)$ \\
\hline GP suspects FH & $14(6.9)$ & $1(8.3)$ & $11(50.0)$ \\
\hline GP does not suspect FH & $186(92.1)$ & $10(83.3)$ & $11(50.0)$ \\
\hline \multicolumn{4}{|l|}{ LDL-C mean mmol/I (IQR) } \\
\hline Maximum LDL-C measurement & $5.20(5.0-5.6)$ & $5.13(4.5-6.0)$ & $5.84(5.3-6.1)$ \\
\hline Pre-treatment LDL-C & $5.63(5.2-5.9)$ & $6.82(6.4-7.3)$ & $9.75(8.8-10.7)$ \\
\hline$\underline{\text { Latest LDL-C measurement }}$ & $3.73(2.8-4.8)$ & $3.44(3.1-4.1)$ & $4.77(4.1-5.5)$ \\
\hline No lipid-lowering therapy & $4.4(3.8-5.2)$ & 3.6() & $3.3(3.1-3.5)$ \\
\hline Lipid-lowering therapy, overall & $2.9(2.5-3.4)$ & $3.4(3.0-4.3)$ & $4.9(4.6-5.6)$ \\
\hline Statins & $2.9(2.5-3.4)$ & $3.4(3.0-4.3)$ & $4.8(4.4-5.5)$ \\
\hline
\end{tabular}

All patients are from the high LDL-C population. DLCN = Dutch Lipid Clinic Network. FH = familial hypercholesterolaemia. LDL-C = low-density lipoprotein cholesterol. PCSK9 = proprotein convertase subtilisin/ kexin type 9.

patients with CVD who were treated with statins were receiving maximum dosage. Among individuals with high LDL-C and no CVD $(n=168)$ the corresponding values were $41.1 \%(n=69)$ receiving lipidlowering therapy and $13.1 \%(n=22)$ reached the target of LDL-C $<2.6 \mathrm{mmol} / \mathrm{l}$ (Table 4). Among patients with CVD and high LDL-C 37 (53.9\%) reached reduction of LDL-C of $>50 \%$, and among patients without CVD 39 (23.4\%) reached a 50\% reduction (data not shown).

\section{Discussion}

\section{Summary}

This study examined the prevalence and management of $\mathrm{FH}$ in general practice. The main findings included that there is still a massive lack of recognition of $\mathrm{FH}$ in general practice. Despite a high LDL-C 
Table 4 Evaluation of lipid-lowering therapy

High LDL-C population (LDL-C $\geq 5.0 \mathrm{mmol} / \mathrm{I}$ ), $n=236, n \%$
Hypercholesterolaemia without potential secondary cause (subgroup), $n=115, n \%$

\section{Patients with CVD diagnoses}

Treatment target - LDL-C >1.8 $\mathrm{mmol} / \mathrm{I}$

Total number of patients

$68(28.8)$

$34(29.6)$

Patients receiving statins

$51(75.0)$

$26(76.5)$

Other lipid-lowering therapy

2 (2.9)

$0(0.0)$

Maximum dosage of statins

$28(54.9)$

$15(57.7)$

Patients reaching treatment target ${ }^{2}$

$3(4.4)$

$2(5.9)$

\section{LDL-C mean mmol/I (IQR)}

Maximum registered

Adjusted pre-treatment

Latest follow-up
$5.16(4.90-5.60)$

$6.36(5.36-6.73)$

$3.31(2.50-4.10)$
$4.94(5.00-5.40)$

$6.51(5.30-7.18)$

$3.44(2.60-4.20)$

Patients without CVD diagnoses

Treatment target - LDL-C > 2.6 mmol/I

\begin{tabular}{lcc} 
Total number of patients & $168(71.2)$ & $81(70.4)$ \\
\hline Patients receiving statins & $67(39.9)$ & $22(27.2)$ \\
\hline Other lipid-lowering therapy & $2(1.2)$ & $0.0)$ \\
\hline Maximum dosage of statins & & $15(68.2)$ \\
\hline Overall & $36(53.7)$ & $10(66.7)$ \\
\hline Possible FH & $28(77.8)$ & $1(6.7)$ \\
\hline Probable FH & $3(8.3)$ & $4(26.7)$ \\
\hline Definite FH & $5(13.9)$ & $6(7.4)$ \\
\hline Patients reaching treatment target & & $6(100)$ \\
\hline Overall & $22(13.1)$ & $0(0.0)$ \\
\hline Possible FH & $22(100)$ & $0(0.0)$ \\
\hline Probable FH & $0(0.0)$ & $0(0.0)$ \\
\hline Definite FH
\end{tabular}

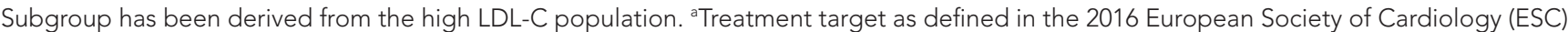
and European Atherosclerosis Society (EAS) guidelines for management of dyslipidaemia. ${ }^{16} \mathrm{CVD}=$ cardiovascular disease. $\mathrm{FH}=$ familial hypercholesteroleamia. LDL-C = low-density lipoprotein cholesterol. 
The study found a low number of patients who reached their treatment target. If a reduction of LDL-C of $>50 \%$ is applied as a criterion for reached treatment target, then 37 (53.9\%) of the patients with CVD reached their treatment target. Among the patients with high LDL-C but no CVD, 39 patients $(23.4 \%)$ reached their treatment target. This figure, however, must be interpreted with caution, as many patients receiving statins have no pre-treatment LDL-C available. In these cases, the pre-treatment LDL-C is estimated from the effect of their lipid-lowering therapy, and the reduction, therefore, reflects this estimation.

\section{Strengths and limitations}

This study relies solely on data provided by records at the GP clinics. The familial history or the past medical history could not be further elaborated on than the available information in patient records, and there was no possibility to verify the LDL-C measurements by follow-up blood tests.

According to the DLCN criteria, FH should be suspected already at a low-density lipoprotein (LDL) level at $4.0 \mathrm{mmol} / \mathrm{l}$. The threshold of $5.0 \mathrm{mmol} / \mathrm{I}$ was chosen, since a considerable proportion of the individuals with an LDL-C between 4.0 and $4.9 \mathrm{mmol} / \mathrm{l}$ will have secondary hypercholesterolaemia. This, of course, will exclude patients with FH with LDL-C levels between 4.0 and $4.9 \mathrm{mmol} / \mathrm{l}$, thereby causing an underestimation of the number of potential patients with $\mathrm{FH}$.

The extent of the true missing values in this dataset cannot be evaluated precisely. The records only reflect positive findings. There might also be an underestimation of registering positive findings, such as tendon xanthomas, arcus cornealis, and family history, thereby underestimating the number of patients with $\mathrm{FH}$.

Only two-thirds of the high LDL-C population had familial medical history available, which will lead to underestimating the prevalence of $\mathrm{FH}$ in this setting. However, this proportion of registration is relatively high compared with other studies. ${ }^{18-20}$

Information regarding first-degree relatives and their diagnoses was obtained from the patient records when mentioned. According to Danish legislation, the records of the patient's relatives cannot be investigated. Therefore, information on CVD or hypercholesterolaemia was entered in the study as a fulfilled criterion of premature CVD or hypercholesterolaemia, even if the age of the relative was not noted. This will of course overestimate the DLCN diagnostic score, but the approach was chosen in order to identify as many individuals with potential $\mathrm{FH}$ as possible.

There is a considerable lack of registration, especially of CVD diagnoses, which is a critical component in the clinical diagnosis of $\mathrm{FH}$. The study found $2.9 \%$ in the entire population $(n=9652)$ versus approximately $9 \%$ as generally estimated in the Danish population. ${ }^{21,22}$

The study population concerns only a quarter $(n=2382,24.6 \%)$ of the entire 9652 individuals and there is no information on the remaining part of the population. However, one must expect that those included in the study population are individuals with symptoms or suspicion of possible sickness; therefore, the incidence of potential FH may be lower in the rest of the group, but, to the authors' knowledge, there are no data to support this thesis.

LDL-C is not measured routinely in general practice in Denmark. The measurement is only performed if the clinical examination of an individual or an individual's risk factors warrants this. The individuals in this study, therefore, might not be a fully random sample of the population, as they have been selected for lipid measurement by their GP owing to medical history or clinical condition.

\section{Comparison with existing literature}

It was found that only one-third of the high LDL-C population had been referred to any cardiology specialist and only four individuals $(1.7 \%)$ to a lipid clinic. These four patients were all deemed to have definite $\mathrm{FH}$. Subsequently, nearly two-thirds of individuals with probable or definite $\mathrm{FH}(61.8 \%$ with DLCN score $>5$ ) were neither diagnosed with, nor suspected of having, FH. This vast majority of individuals with $\mathrm{FH}$ were not being identified in primary care, this has also been found in other studies. $^{23,24}$

In this study screening within the primary healthcare database was successful in detecting a provisional diagnosis of FH. This is in line with what has been found in other studies. ${ }^{25-28}$

Numerous definitions have been suggested during the last decade on adequate treatment in $\mathrm{FH}$, but no evidence-based clinical trials on treatment goals exist. At the time of data collection in this study, the recommendation in Denmark was the same as in the ESC 2016 guidelines on CVD 
prevention in clinical practice: high risk $<2.6 \mathrm{mmol} / \mathrm{l}(<100 \mathrm{mg} / \mathrm{dl})$ or a reduction of at least $50 \%$ if the baseline is between 2.6 and $5.2 \mathrm{mmol} / \mathrm{l}(100-200 \mathrm{mg} / \mathrm{dl})$; and for very high risk $<1.8 \mathrm{mmol} / \mathrm{l}$ or reduction of at least $50 \%$ if the baseline is between 1.8 and $3.5 \mathrm{mmol} / \mathrm{l}(70-135 \mathrm{mg} / \mathrm{dl}){ }^{16,29}$

This lack of sufficient treatment is illustrated by the levels of LDL-C, which remained high even in the high-risk individuals. The proportion of patients reaching absolute LDL-C targets was low as well: among patients with CVD only $4.4 \%$ reached the treatment target of LDL-C $<1.8 \mathrm{mmol} / \mathrm{l}$, even though 77.9\% received lipid-lowering therapy. In this population $53.9 \%$ of the patients with CVD had their baseline LDL-C value reduced by $>50 \%$. This means that almost half of the patients did not reach their treatment target.

Despite the fact that many individuals do not reach their treatment target, only half of the high LDL-C population were on lipid-lowering therapy. These findings correspond well with findings in a previous population study. ${ }^{10}$ In addition, less than one-third of the individuals in the high LDL-C population receiving statins were treated to maximum dosage. This emphasises a need for better care. Only a few patients received ezetimibe but this may reflect that ezetimibe was only eligible for a subsidy from the state in 2018 and, thus, during the study period was quite expensive compared with statins. In Denmark, PCSK9 inhibitors are dispensed free of charge, but only cardiologists, endocrinologists, and neurologists can prescribe PCSK9 inhibitors. The state has set a limit for LDL of >3-4 mmol/l depending on the underlying disease and patients must be treated to the maximum tolerated dose of statin and ezetimibe before PCSK9 inhibitors can be delivered.

These factors may have influenced the level of treatment. At present, the 2019 ESC and EAS guidelines for the management of dyslipidaemia establishes a treatment target of LDL-C $<1.4 \mathrm{mmol} / \mathrm{I}$ for individuals at very high risk and LDL-C $<1.8 \mathrm{mmol} / \mathrm{l}$ for individuals at high risk. ${ }^{17}$ In this context, most of the individuals in this population would probably fail to reach their treatment target.

\section{Implications for research and practice}

In this study the possibility of determining the prevalence of $\mathrm{FH}$ from pre-recorded information has been examined. The WinPLC patient record system was used for identifying diagnoses and levels of biochemical markers before manually reading through the patient records. It has been shown that clinical case-finding algorithms, such as TARB-Ex system and FAMCAT, are useful in identifying patients in primary care suspected of $\mathrm{FH} .{ }^{23,30,31}$ The study identified several potential patients with $\mathrm{FH}$, which strongly suggests that a similar system could be a valuable addition to the Danish electronic patient records in general practice. The use of electronic reminders combined with potential patients with $\mathrm{FH}$ being identified by electronic data extraction at the general practice has shown to raise the rate of referred patients for further diagnostics at a specialist lipid clinic. ${ }^{32}$

In collaboration with the biochemical laboratories, a high LDL could automatically be accompanied by a marker stating that individuals with a high LDL should be suspected of $\mathrm{FH}$ and family investigation considered. ${ }^{27,33}$ Similarly, an electronic message could automatically be forwarded to the general practice by the electronic patient record system whenever a diagnosis of, for instance, $\mathrm{MI}$, ischaemic heart disease, or stroke is registered to an individual aged $<55-60$ years in order to identify potential $\mathrm{FH}$ and initiate cascade screening. A combination of a registered high LDL-C and a diagnosis of CVD at a young age could also trigger an automatic notification. Such electronic aids could serve to raise awareness of potential FH among GPs.

Over the last decade, there has been considerable focus on $\mathrm{FH}$ and many initiatives have already been launched. A global overview of the current status of $\mathrm{FH}$ has been published recently and guidelines for detecting and treating $\mathrm{FH}$ have been provided. 4,10 As a result of this and other initiatives, the number of diagnosed patients with $\mathrm{FH}$ must be expected to increase. In Denmark the estimated number of diagnosed patients with $\mathrm{FH}$ has increased from about $4 \%$ to at least $13 \%$ in a few years. ${ }^{4,10}$ However, this study confirms that there is still a massive lack of recognition and treatment of $\mathrm{FH}$ in general practice. Primary care has a key role in diagnosis and significant potential exists in primary care to identify new cases of $\mathrm{FH}$ who could also act as new index cases for a family screening programme. Studies have shown that GPs consider themselves to be a key figure in diagnosing $\mathrm{FH}$, but there is a lack of knowledge on how to handle these patients. ${ }^{34,35}$

There is a need for an education programme and a better diagnostic work-up including collaboration with the biochemical laboratories. Thus, several screening options have been suggested, including a clinical case-finding algorithm, a marker when a high level of LDL-C is registered on a blood test, or 
when diagnosis of CVD at a young age is registered. Support from other providers within the primary care setting or triaging to genetics healthcare professionals is needed. ${ }^{2}$ Finally, there is a need to increase awareness of $\mathrm{FH}$ in the general population so that the population becomes aware of the importance of a health check if there are family members with high cholesterol or early CVD. Future research is desired to evaluate a broader implementation of the above regarding detection of $\mathrm{FH}$ in general practice, early treatment, and the effect on cardiovascular outcomes.

Funding

This work was funded by Amgen Inc. (grant reference number: ISS 20159575).

\section{Ethical approval}

This study was approved by the Danish Patient Safety Authorities and the National Ethics Committee (reference number: $\mathrm{H}-16029641$ ).

\section{Provenance}

Freely submitted; externally peer reviewed.

\section{Acknowledgements}

The authors would like to thank their good colleagues in general practice: GPs Tina Koch, Hanne Hjortkjaer-Petersen, Camilla Brand, and Thomas Drivsholm at the practitioner clinic Lægehuset Noerre Farimagsgade 33, and GP Pernille Stage for their help in collecting data.

\section{References}

1. Gidding SS, Champagne MA, de Ferranti SD, et al. The agenda for familial hypercholesterolemia: a scientific statement from the American heart association. Circulation 2015; 132(22): 2167-2192. DOI: https://doi.org/10. 1161/CIR.0000000000000297

2. Defesche JC, Gidding SS, Harada-Shiba M, et al. Familial hypercholesterolaemia. Nat Rev Dis Primers 2017; 3(1): 17093. DOI: https://doi.org/10.1038/nrdp.2017.93

3. Benn M, Watts GF, Tybjærg-Hansen A, Nordestgaard BG. Mutations causative of familial hypercholesterolaemia: screening of 98098 individuals from the Copenhagen general population study estimated a prevalence of 1 in 217. Eur Heart J 2016; 37(17): 1384-1394. DOI: https://doi.org/10.1093/eurheartj/ehw028

4. EAS Familial Hypercholesterolaemia Studies Collaboration, Vallejo-Vaz AJ, De Marco M, et al. Overview of the current status of familial hypercholesterolaemia care in over 60 countries - the EAS familial hypercholesterolaemia studies collaboration (FHSC. Atherosclerosis 2018; 277: 234-255. DOI: https://doi.org/10.1016/j.atherosclerosis. 2018.08.051

5. Akioyamen LE, Genest J, Shan SD, et al. Estimating the prevalence of heterozygous familial hypercholesterolaemia: a systematic review and meta-analysis. BMJ Open 2017; 7(9): e016461. DOI: https://doi.org/10.1136/bmjopen2017-016461

6. Watts GF, Shaw JE, Pang J, et al. Prevalence and treatment of familial hypercholesterolaemia in Australian communities. Int J Cardiol 2015; 185: 69-71. DOI: https://doi.org/10.1016/j.ijcard.2015.03.027

7. Schofield J, Kwok S, France M, et al. Knowledge gaps in the management of familial hypercholesterolaemia. A UKbased survey. Atherosclerosis 2016; 252: 161-165. DOI: https://doi.org/10.1016/j.atherosclerosis.2016.07.009

8. Descamps OS, Van Caenegem O, Hermans MP, et al. A Belgian consensus strategy to identify familial hypercholesterolaemia in the coronary care unit and its subsequent cascade screening and treatment: BEL-FaHST (the Belgium familial hypercholesterolaemia strategy). Atherosclerosis 2018; 277: 369-376. DOI: https://doi.org/10. 1016/j.atherosclerosis.2018.05.037

9. Bell DA, Garton-Smith J, Vickery A, et al. Familial hypercholesterolaemia in primary care: knowledge and practices among general practitioners in Western Australia. Heart, Lung Circ 2014; 23(4): 309-313. DOI: https://doi.org/10. 1016/j.hlc.2013.08.005

10. Nordestgaard BG, Chapman MJ, Humphries SE, et al. Familial hypercholesterolaemia is underdiagnosed and undertreated in the general population: guidance for clinicians to prevent coronary heart disease: consensus statement of the European Atherosclerosis Society. Eur Heart J 2013; 34(45): 3478-3490. DOI: https://doi.org/10. 1093/eurheartj/eht273

11. Benn M, Watts GF, Tybjaerg-Hansen A, Nordestgaard BG. Familial hypercholesterolemia in the Danish general population: prevalence, coronary artery disease, and cholesterol-lowering medication. J Clin Endocrinol Metab 2012; 97(11): 3956-3964. DOI: https://doi.org/10.1210/jc.2012-1563

12. Vallejo-Vaz AJ, Kondapally Seshasai SR, Cole D, et al. Familial hypercholesterolaemia: a global call to arms. Atherosclerosis 2015; 243(1): 257-259. DOI: https://doi.org/10.1016/j.atherosclerosis.2015.09.021

13. Lamberts $\mathrm{H}$. The International Classification of Primary Care (ICPC): new applications in research and computerbased patient records in family practice. Fam Pract 1996; 13(3): 294-302. 
14. Larsen MK, Nissen PH, Kristensen IB, et al. Sudden cardiac death in young adults: environmental risk factors and genetic aspects of premature atherosclerosis. J Forensic Sci 2012; 57(3): 658-662. DOI: https://doi.org/10.1111/j. 1556-4029.2011.02028.x

15. Besseling J, Kindt I, Hof M, et al. Severe heterozygous familial hypercholesterolemia and risk for cardiovascular disease: a study of a cohort of 14,000 mutation carriers. Atherosclerosis 2014; 233(1): 219-223. DOI: https://doi. org/10.1016/j.atherosclerosis.2013.12.020

16. Catapano AL, Graham I, De Backer G, et al. 2016 ESC/EAS guidelines for the management of dyslipidaemias. Rev Esp Cardiol 2017; 70(2): 115. DOI: https://doi.org/10.1016/j.rec.2017.01.002

17. Mach F, Baigent C, Catapano AL, et al. 2019 ESC/EAS guidelines for the management of dyslipidaemias: lipid modification to reduce cardiovascular risk. Eur Heart J 2020; 41(1): 111-188. DOI: https://doi.org/10.1093/ eurheartj/ehz455

18. Dhiman P, Kai J, Horsfall L, et al. Availability and quality of coronary heart disease family history in primary care medical records: implications for cardiovascular risk assessment. PLoS One 2014; 9(1): e81998. DOI: https://doi. org/10.1371/journal.pone.0081998

19. Hall R, Saukko PM, Evans PH, et al. Assessing family history of heart disease in primary care consultations: a qualitative study. Fam Pract 2007; 24(5): 435-442. DOI: https://doi.org/10.1093/fampra/cmm037

20. Qureshi N, Armstrong S, Dhiman P, et al. Effect of adding systematic family history enquiry to cardiovascular disease risk assessment in primary care: a matched-pair, cluster randomized trial. Ann Intern Med 2012; 156(4): 253-262. DOI: https://doi.org/10.7326/0003-4819-156-4-201202210-00002

21. Danish Heart Foundation. [Heart statistics]. [Article in Danish]. 2016; https://hjerteforeningen.dk/alt-om-dit-hjerte/ noegletal (accessed 19 Jan 2021).

22. Danish Statistics. [Statbank]. [Article in Danish]. 2020; https://www.statistikbanken.dk/statbank5a/default.asp?w= 1436 (accessed 14 Oct 2020).

23. Weng S, Kai J, Akyea R, Qureshi N. Detection of familial hypercholesterolaemia: external validation of the FAMCAT clinical case-finding algorithm to identify patients in primary care. Lancet Public Health 2019; 4(5): e256-e264. DOI: https://doi.org/10.1016/S2468-2667(19)30061-1

24. Gray J, Jaiyeola A, Whiting $M$, et al. Identifying patients with familial hypercholesterolaemia in primary care: an informatics-based approach in one primary care centre. Heart 2008; 94(6): 754-758. DOI: https://doi.org/10.1136/ hrt.2006.107391

25. Green P, Neely D, Humphries SE, et al. Improving detection of familial hypercholesterolaemia in primary care using electronic audit and nurse-led clinics. J Eval Clin Pract 2016; 22(3): 341-348. DOI: https://doi.org/10.1111/jep. 12481

26. Schmidt N, Schmidt B, Dressel A, et al. Familial hypercholesterolemia in primary care in Germany. Diabetes and cardiovascular risk evaluation: targets and essential data for commitment of treatment (detect) study. Atherosclerosis 2017; 266: 24-30. DOI: https://doi.org/10.1016/j.atherosclerosis.2017.08.019

27. Kirke AB, Barbour RA, Burrows $S$, et al. Systematic detection of familial hypercholesterolaemia in primary health care: a community based prospective study of three methods. Heart Lung Circ 2015; 24(3): 250-256. DOI: https:// doi.org/10.1016/j.hlc.2014.09.011

28. Pang J, Chan DC, Hu M, et al. Comparative aspects of the care of familial hypercholesterolemia in the "Ten Countries Study". J Clin Lipidol 2019; 13(2): 287-300. DOI: https://doi.org/10.1016/j.jacl.2019.01.009

29. Piepoli MF, Hoes AW, Agewall S, et al. 2016 European guidelines on cardiovascular disease prevention in clinical practice: The Sixth Joint Task Force of the European Society of Cardiology and other societies on cardiovascular disease prevention in clinical practice (constituted by representatives of 10 societies and by invited experts) developed with the special contribution of the European Association for Cardiovascular Prevention \& Rehabilitation (EACPR). Eur Heart J 2016; 37(29): 2315-2381. DOI: https://doi.org/10.1093/eurheartj/ehw106

30. Kirke A, Watts GF, Emery J. Detecting familial hypercholesterolaemia in general practice. Aust Fam Physician 2012; 41(12): 965-968.

31. Troeung L, Arnold-Reed D, Chan She Ping-Delfos W, et al. A new electronic screening tool for identifying risk of familial hypercholesterolaemia in general practice. Heart 2016; 102(11): 855-861. DOI: https://doi.org/10.1136/ heartjnl-2015-308824

32. Qureshi N, Weng S, Tranter J, et al. Feasibility of improving identification of familial hypercholesterolaemia in general practice: intervention development study. BMJ Open 2016; 6(5): e011734. DOI: https://doi.org/10.1136/ bmjopen-2016-011734

33. Bell D, Hooper A, Bender R, et al. Opportunistic screening for familial hypercholesterolaemia via a community laboratory. Heart Lung Circ 2012; 21(Supplement 1): S70. DOI: https://doi.org/10.1016/j.hlc.2012.05.177

34. Kwok S, Pang J, Adam S, et al. An online questionnaire survey of UK general practitioners' knowledge and management of familial hypercholesterolaemia. BMJ Open 2016; 6(11): e012691. DOI: https://doi.org/10.1136/ bmjopen-2016-012691

35. Zimmerman J, Duprez D, Veach PM, Zierhut HA. Barriers to the identification of familial hypercholesterolemia among primary care providers. J Community Genet 2019; 10(2): 229-236. DOI: https://doi.org/10.1007/s12687018-0383-3 